\title{
Human health impacts in a changing South African climate
}

\author{
C Y Wright, ${ }^{1,2} \mathrm{PhD}$ (Public Health); R M Garland, ${ }^{1,3} \mathrm{PhD}$ (Chemistry); M Norval, ${ }^{4}$ DSc (Virology); \\ C Vogel, ${ }^{5} \mathrm{PhD}$ (Geography and Environmental Studies) \\ ${ }^{1}$ Climate Studies, Modelling and Environmental Health Research Group, Council for Scientific and Industrial Research, Pretoria, South Africa \\ ${ }^{2}$ Department of Geography, Geoinformatics and Meteorology, University of Pretoria, Pretoria, South Africa \\ ${ }^{3}$ Climatology Research Group, Unit for Environmental Sciences and Management, North West University, Potchefstroom, South Africa \\ ${ }^{4}$ Biomedical Sciences, University of Edinburgh Medical School, Edinburgh, UK \\ ${ }^{5}$ Centre for Environmental Management, Department of Geography, Geoinformatics and Meteorology, University of Pretoria, Pretoria, South Africa
}

Corresponding author: CYWright (cwright@csir.co.za)

Climate change is projected to lead to warmer temperatures, especially in southern Africa, where the warming is predicted to be $2^{\circ} \mathrm{C}$ higher than the global increase. Given the high burden of disease already associated with environmental factors in this region, this temperature increase may lead to grave challenges for human health and quality of life. HIV/AIDS, poverty, food and water insecurity together with inequality and unemployment will further complicate the manner in which we will need to address the challenges of a changing climate. The health impacts are direct, such as increased temperatures leading to heat exhaustion, and indirect, such as likely increases in infectious diseases from contaminated water and changes in the distribution and/or magnitude of vector-borne diseases. The most effective measures for adapting to climate change to ensure healthy populations are to implement basic public health systems and services. These range from a continuous supply of clean water to adequate primary healthcare services. Support for required interventions is required not only from government, but also from healthcare professionals and communities. The need for disease surveillance, data capturing and more focused research is paramount.

S Afr Med J 2014;104(8):579-582. DOI:10.7196/SAMJ.8603

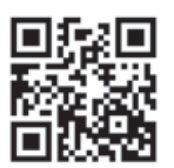

Projections show that the impacts of a changing climate in Africa will vary by region, and that southern Africa will experience, on average, a warming of approximately $2^{\circ} \mathrm{C}$ higher than the predicted average global increase by the end of the century, with possible changes in the frequency and intensity of rainfall across various regions. These temperature and rainfall changes may lead to serious challenges when compounded by local vulnerabilities. A high burden of existing diseases, in particular HIV/AIDS, poverty, water and food insecurity, and often inadequate public health services, increase the vulnerability to climate-related health threats. The latest findings of the Intergovernmental Panel on Climate Change (IPCC) ${ }^{[1]}$ confirm that the largest human health risks caused by climate change will be among communities and populations currently most affected by climate-related diseases. It is clear that human influences have led to the warming climate currently being experienced, which will continue into the future. Extreme weather events and Arctic ice loss, among other changes, have resulted from an estimated average temperature rise of just less than $1^{\circ} \mathrm{C}$ since the turn of the 20th century (similar information is not available for South Africa (SA)). Unless an immediate and concerted effort is made to reduce greenhouse gas emissions, future threats of further global warming, i.e. a rise in sea level, loss of biodiversity, exacerbation of climate-related diseases, will continue to increase.

In southern Africa, the need for more focused research and intervention, control and eradication of vector- and water-borne diseases, respiratory conditions and cardiovascular illnesses, among others, is paramount. While a number of other factors including governance and better and more critical health-focused research are needed, it is clear that an integrated, multidisciplinary and co-ordinated response is required to curb the health risks projected from future climate changes. This article considers these health risks in the SA context, highlighting areas that need special attention.

\section{A South African perspective}

For SA, empirical evidence from regionally measured temperatures in recent decades shows that the rate of increase in annual maximum and minimum temperatures has been rising. ${ }^{[2]}$ Based on sophisticated climate model ensembles, including the General Circulation Model projections and relevant downscaling of these models to more localised situations, climate projections for SA and the rest of Africa indicate a future warming in temperature of $>2^{\circ} \mathrm{C}$ than the global average. ${ }^{[2,3]}$ Given such changes, there will probably be significant health consequences for climate-related diseases and subsequently the quality of life for South Africans. Table 1 shows the top ten causes of death in SA, based on the most recent data for this type of analysis. A quadruple burden of disease is evident, with HIV/AIDS, chronic diseases, poverty-related conditions and injuries appearing as the leading causes of mortality. Climate change may increase these figures, as well as adding emerging or re-emerging diseases to the total burden.

\section{Direct effects \\ Temperature}

Internationally, there is ample evidence of the links between weather and health; however, there is very little information on these relationships in tropical and sub-tropical developing and emerging countries. ${ }^{[4]}$ The majority of studies have been performed in temperate climates and/or industrial economies. ${ }^{[4]}$ In these studies, the threshold value where health is impacted by heat varies, as does the portion of the population that are most vulnerable to health impacts from extreme temperatures. ${ }^{[4]}$ In SA, the large concern for 
public health is around extreme hot events, rather than extreme cold events, and how the impact of these events may change into the future.

Model projections for temperature in a changing climate for the globe and the African region indicate increases in temperature and heat waves, both of which have the potential to impact adversely on human health. Physiologically, when the temperature of the human body rises above $38^{\circ} \mathrm{C}$, heat exhaustion can occur, while heat stroke is possible $>40.6^{\circ} \mathrm{C}^{[4]}$ (see the article by Kjellstrom et al..$\left.^{[5]}\right)$. However, exposure to ambient temperatures higher than body temperature may have major health impacts, ranging from respiratory and cardiovascular effects to death. For example, Baccini et al. ${ }^{[6}$ investigated the impact of heat on mortality in 15 European cities. They identified temperature thresholds associated with a minimum mortality rate; for the 15 cities these thresholds ranged from an apparent temperature of $21.5^{\circ} \mathrm{C}$ in Ljubljana, Slovenia, to an apparent temperature of $32.7^{\circ} \mathrm{C}$ in Athens, Greece. Apparent temperature aims to describe how hot it feels, and was calculated using a combination of temperature and dew point. ${ }^{[7]}$ In general, the temperature-mortality relationship follows a non-linear, U, J or V shape, with health impacts from heat increasing rapidly and non-linearly at temperatures above those associated with minimal mortality. ${ }^{[6,8,9]}$ Only one study has investigated such a relationship in Cape Town, SA. However, the results were inconclusive and it is unclear how these results might apply to other parts of the country. ${ }^{[10]}$ Previous work in SA has focused on occupational health. ${ }^{[11,12]}$ As there is evidence that there is already a rate of increase in maximum and minimum temperatures in $\mathrm{SA}^{[13]}$ there is a major potential impact of extreme temperatures on health. Additional research is needed to understand the magnitude of the potential problem and to identify vulnerable communities.

\section{Indirect effects \\ Infectious diseases}

The spread of enteric, water-borne diseases is likely to alter with changing climatic conditions in SA. Flooding and droughts affect the flow of rivers, leading to more contamination by enteroviruses and other pathogenic micro-organisms. Drinking water supplies may become polluted with faeces, resulting in outbreaks of diarrhoeal diseases such as cholera and dysentery.

The incidence and distribution of vectorborne diseases are predicted to change in
SA. The geographical spread and disease burden of malaria may alter, depending on how well control programmes are adapted. Tick-borne encephalitides, dengue fever and plague are predicted to increase. ${ }^{[14]}$ The last recorded death from plague in SA was in Coega in 1982, ${ }^{[15]}$ but anecdotal evidence suggests that rat infestations are on the rise, especially in the City of Tshwane, Gauteng.

Thought may also need to be given to food-borne infections, such as salmonellosis, which is relatively common in SA and may increase with changing temperatures in the future, particularly where the electricity supply is unreliable or non-existent. Changes in land use caused by altered rainfall patterns and temperatures may lead to population displacement, violence and increased risktaking behaviours, which could cause a rise in the transmission of sexually transmitted infections such as HIV (see the article by Abayomi and Cowan ${ }^{[16]}$ ).

\section{Respiratory illnesses}

Mining, traffic, industry, biomass burning and domestic fuel burning are among the key contributors to air pollution in SA. Despite the implementation of stricter air quality legislation, air pollution is still a serious problem in the country, particularly on the Highveld, in the Vaal Triangle, the Durban South Basin and large cities, such as Johannesburg and Cape Town.

Climate change and air pollution are closely interlinked, given that in SA they are primarily driven by emissions from the combustion of fossil fuels. While this means that there are significant co-benefits for climate and air quality from reducing atmospheric emissions, the challenges to enact such decreases are large. Changes in emissions are likely to be varied here - possible reductions in the release of industrial greenhouse gases compared with continued domestic reliance on the burning of wood and coal. Currently, mortality from lower respiratory illnesses ranks sixth in the country's burden of disease profile. However, this may be exacerbated should, for example, surface-levels of tropospheric ozone, air-borne pollens and spores, and other air pollutants increase. Poor air quality also affects cardiovascular health, weakening this system and increasing the risk of stroke and cardiac failure. Additionally, changes in meteorology and climate, such as largescale weather circulation patterns, rainfall, temperature and cloud cover, can have an impact on the transport and formation of pollutants, and thus climate change may have a direct effect on air pollution in SA. It is likely that surface-level ozone and particulate matter, ${ }^{[4]}$ two factors that currently contribute greatly to air pollution in SA, could be most affected by climate change.

Indoor air pollution is also a grave concern - smoky cooking fuels are a serious health hazard in developing countries, including SA, especially for women and children. Approximately $20 \%$ of SA households are exposed to smoke from burning fossil fuels. ${ }^{[17}$ While the electrification programme in SA aims to bring electricity to all households, studies show that some households prefer not to use electricity for cooking and heating because of the cost and also for cultural reasons. These and other issues may hinder interventions that strive to reduce air pollution and associated health impacts.

Impacts on agriculture, food production and fisheries

Direct health-related impacts and attribution to climate change stresses are

Table 1. All-person top 10 specific causes of death in South Africa, 2000 ${ }^{[36]}$

\begin{tabular}{|c|c|c|c|}
\hline Rank & Cause of death & $\begin{array}{l}\text { Premature mortality burden - } \\
\text { years of life lost }{ }^{*}\end{array}$ & $\%$ \\
\hline 1 & HIV/AIDS & 4665410 & 39.0 \\
\hline 2 & Homicide/violence & 902592 & 7.5 \\
\hline 3 & Tuberculosis & 595277 & 5.0 \\
\hline 4 & Road traffic accidents & 489979 & 4.1 \\
\hline 5 & Diarrhoeal diseases & 452827 & 3.8 \\
\hline 6 & Lower respiratory infections & 449010 & 3.8 \\
\hline 7 & Low birth weight & 393763 & 3.3 \\
\hline 8 & Stroke & 318083 & 2.7 \\
\hline 9 & Ischaemic heart disease & 284438 & 2.4 \\
\hline 10 & Protein-energy malnutrition & 171433 & 1.4 \\
\hline
\end{tabular}


hard to identify (some of these are addressed in the accompanying article by Bowles and Butler ${ }^{[18]}$ ). Other perhaps indirect but equally important associations, including food security via food ingestion, are even more difficult to attribute to changes in the climate system. Notwithstanding these limitations, there is a growing cohort of plausible assessments showing that the links between climate change, agriculture, such as in the crop, livestock and fishery sectors, food security and ultimately health, are important and need to be the focus of more intensified research (see the latest IPCC 5th Assessment Reports $^{[1]}$ ). Some of these interactions are highlighted below.

Climate change, including variability, most notably periods of extreme floods and drought, is well known to have significant impacts on agriculture in SA and the rest of the African continent. For example, the droughts associated with the early 1980s and 1990s triggered severe shortfalls in crop and livestock production and prompted the establishment of Vulnerability Assessment Committees to enable interventions based not only on cereal shortfalls but also on the role of HIV/AIDS and other factors influencing access to food. ${ }^{[19,20]}$

More recent assessments ${ }^{[1]}$ show that climate change will continue to have a negative impact on parts of Africa, with 'knock-on' consequences for the environment and society. Africa will be affected by drought, largely in the northern and southwestern portions of the continent, while towards the east, areas of increased rainfall are usually predicted. Climate variability and the role of critical drivers for the African continent, such as the El Niño Southern oscillation, ${ }^{[21]}$ have had and will continue to have a critical influence on the links between climate, agriculture, food security and health, although these linkages require more investigation. Water is a vehicle through which certain factors that impact on health are transmitted, with significant outbreaks of cholera, often after a high rainfall event or period (see, for example, links to human health, climate change and water quality ${ }^{[22]}$.

The role of 'human dimensions', political economy and 'power' relations should not be ignored when examining the very important linkages and 'nexus' between climate change, global environmental change, globalisation, agriculture, food security and the growing 'hot spots' of global environmental change in various African urban and peri-urban centres. ${ }^{[23-28]}$ Climate change does not occur in a vacuum and the impacts are therefore not imprinted on a blank, neutral canvas. Some emerging concerns are profiled below.

Just as in the medical or any other scientific field, how one frames the problem (the paradigm used in the case of climate and environmental change), ${ }^{[29]}$ and governance and government (how the problem is managed), ${ }^{[30]}$ are important starting considerations that can profoundly shape the resultant narrative and understanding of the impact of climate change on health. The interacting roles of food price shocks, economic stability that influences access to food ${ }^{[4]}$ and land, including land tenure issues, agricultural support and the growing role of land grabs and biofuels, ${ }^{[4]}$ all ultimately influence who accesses food and health resources. Issues of equity and justice, such as who decides what is grown, where and how it is grown and in terms of health, and who accesses insurance in times of stress, ${ }^{[31]}$ are critical dimensions that also shape the relationship between health and climate change.

Designing appropriate interventions at various scales to bolster and enhance the resilience of food systems to various changes, including in the climate and associated socioeconomic and cultural dimensions', therefore requires more careful and focused research. Some systemic analyses of the issue are emerging. The recent Consultative Group on International Agricultural Research (CGIAR) Climate Change, Agriculture and Food Security (CCAFS $)^{32]}$ research effort provides a useful set of results, particularly regarding food systems and climate change and implications for a range of security issues, including health. More local efforts and practical research and intervention, together with the re-examination of community-based approaches to primary healthcare, are needed. These can have policy implications for effective climate change strategies. ${ }^{[33]}$

\section{Concluding remarks}

Apart from the need to address the root cause of climate change and curb carbon dioxide emissions, there is also a requirement to respond to the health risks of a changing climate by making appropriate choices and decisions. It has been found that the risks of climate change come from a vulnerability or lack of preparedness, and exposure of people or assets overlapping with hazards that trigger climate events or trends. ${ }^{[3,4]}$ Climate change also interacts with other stresses to increase risk. This is the case for many of the climate-related human diseases faced by populations (often the most vulnerable ones).

It has been reported ${ }^{[3,4]}$ that the most effective measures for adapting to climate change to ensure healthy populations are to implement basic public health systems and services. These include providing clean water, sanitation and essential primary healthcare (including vaccination and child health services), increasing disaster preparedness and response, raising awareness and education, and alleviating poverty. Currently, approximately 
$91 \%$ of SA households have access to piped water - inside the yard or dwelling, or outside the yard, ${ }^{[34]}$ indicating that significant efforts can achieve such goals. Actions that reduce greenhouse gas emissions may also result in co-benefits, e.g. a shift to cleaner energy sources reduces health-damaging and climate-altering air pollutants.

While it seems that many of the actions needed to address climate change and alleviate subsequent health impacts are aimed at international and national decision-makers and implementers of policy, there are several that can be considered by health scientists and medical professionals. Lobbying for the adoption of renewable energy sources and influencing the attitudes and behaviour of key professionals in the abovementioned organisations are important. Alliances of medical and other health professionals, such as The Global Climate and Health Alliance, and Health Care Without Harm, promote working together to ensure that health is integrated into global, national and local responses to climate change. They also encourage the health sector to mitigate and adapt to climate change. In a letter to the Editor of The Times, ${ }^{[35]}$ more than 60 leading physicians and medical scientists called for an urgent response to climate change, emphasising that no action will inevitably lead to great human suffering. SA health scientists and others working in the health sector are urged to prepare for changes, seek co-benefits and collaborate to ensure the health and well-being of the entire population.

\footnotetext{
References

1. Intergovernmental Panel on Climate Change (IPCC). http://www.ipcc.ch (accessed 25 June 2014). 2. Department of Environmental Affairs, Agriculture, Forestry and Fisheries. Long-Term Adapation Scenarios, 2013/2014. http://www.environment.gov.za (accessed 25 June 2014).

3. Niang I, Ruppel OC, Abdrabo M, et al. Africa. In: Field CB, Barros V, Dokken DJ, et al., eds. Impacts, Adaptation and Vulnerability. Contribution of Working Group II to the Fifth Assessment Report of the Intergovernmental Panel on Climate Change. Cambridge, UK. Cambrid University Press, 2014

4. Smith KR, Woodward A, Campbell-Lendrum D, et al. Human health: Impacts, adaptation and co-benefits In: Field $\mathrm{CB}$, Barros V, Dokken DI, et al, eds. Impacts, Adaptation and Vulnerability Contribution of Working Group II to the Fifth Assessment Report of the Intergovernmental Panel on Climate Change. Cambridge, UK: Cambridge University Press, 2014.

5. Kjellstrom T, Lemke B, Hyatt O, Otto M. Climate change and occupational health: A South African perspective. S Afr Med J 2014;104(8):586. [http://dx.doi.org/10.7196/SAMJ.8646]

6. Baccini M, Biggeri A, Accetta G, et al. Heat effects on mortality in 15 European cities. Epidemiology 2008:19(5):711-719. [http://dx.doi.org/10.1097/EDE.0b013e318176bfcd]

7. Steadman RG. The asessment of sultriness. Part II. Effects of wind, extra radiation and barometric pressure on apparent tssmert 0450(1979)018<0874:TAOSPI $>2.0$.CO;2]

8. Ballester I Robine JM, Herma 8. Ballester Jobine ncomms 1360 ]
}

9. McMichael AJ, Woodruff RE, Hales S. Climate change and human health: Present and future risks. Lancet 2006:367:859-869. [http://dx. doi.org/10.1016/S0140-6736(06)68079-3]

10. McMichael AI Wilkinson P, Kovats RS, et al. International study of temperature, heat and urban mortality: The 'ISOTHURM' project. International Journal of Epidemiology 2008;37:1121-1131. [http://dx.doi org $/ 10.1093 /$ ije/dyn086]

11. Wyndham CH. A survey of causal factors in heat stroke and of their prevention in the gold mining industry Journal of the South African Institute of Mining and Metallurgy 1965;66:125-156.

12. Mathee A, Oba J, Rose A. Climate change impacts of working people (the HOTHAPS initiative): Findings of the South African pilot study. Global Health Action 2010:3. [http://dx.doi.org/10.3402/ gha.v3i0.5612

13. Davis C. Climate Risk and Vulnerability: A Handbook for Southern Africa. South African Risk and Vulnerability Atlas. Pretoria: Council for Scientific and Industrial Research, 2011

14. Myers J, Young T, Galloway M, Manyike P, Tucker T. A public health approach to the impact of climate change on health in southern Africa - identifying priority modifiable risks. S Afr Med 2011;101(11):817-82

15. Department of Health. National Plague Control Guidelines. Pretoria: Department of Health, 2003

16. Abayomi A, Cowan MN. The HIV/AIDS epidemic in South Africa: Convergence with tuberculosis socioecological vulnerability, and climate change patterns. S Afr Med J 2014;104(8):583. [http://dx.do org/10.7196/SAMJ.8645]

17. Norman R, Barnes B, Mathee AM, Bradshaw D, and the South African Comparative Risk Assessmen Collaborating Group. Estimating the burden of disease attributble to indoor air pollution from household use of solid fuels in South Africa in 2000. S Afr Med J 2007;97(8):764-771.

18. Bowles DC, Butler CD. Socially, politically and economically mediated health effects of climate chang Possible consequences for Africa. S Afr Med J 2014;104(8):585. [http://dx.doi.org/10.7196/SAMJ.8604]

19. Vogel CH, Moser S, Kasperson R, Daebelko G. Linking vulnerability, adaptation and resilience science to practice: Pathways, players and partnerships. Global Environmental Change 2007;17:349-364. [http:// dx.doi.org/10.1016/.jgloenvcha.2007.05.002]

20. Drimie S, Gillespie S. Adaptation to climate change in southern Africa: Factoring in AIDS. Environmental Science and Policy 2010;13(8):778-784. [http://dx.doi.org/10.1016/j.envsci.2010.07.03]

21. Landman WA, Botes S, Goddard L, Shongwe M. Assessing the predictability of extreme rainfal seasons over southern Africa. Geophysical Research Letters 2005;32:L23818. [http://dx.dol. org/10.1029/2005GL023965

22. Department of Water Affairs. National Water Resources Strategy: Water for an Equitable and Sustainable Future. 2nd ed. Pretoria: Department of Water Affairs, 2013

23. Devereux S, Maxwell S. Food Security in Sub-Saharan Africa. Pietermaritzburg: ITDG Publishing and University of Natal Press, 2001

24. Institute of Development Studies (IDS). New Directions for African Agriclture. IDS Bulletin 2006;36:2.

25. Leichenko RM, O’Brien KL. Environmental Change and Globalization, Double Exposures. Oxford: Oxford University Press, 2008

26. Fussel H-M, Ebi KL. Assessing vulnerability and human health. In: Patt AG, Schroter D, Klein RJ, de la Vega-Leinart, AC, eds. Assessing Vulnerability to Global Environmental Change - Making Research Usefu for Adaptation Decision Making and Policy. London: Earthscan, 2009:115-132.

27. Ingram JSI, Ericksen P, Liverman D, eds. Food Security and Global Environmental Change. London: Earthscan, 2010.

28. Crush J, Frayne B, Wade P. The crisis of food insecurity in African cities. Journal of Hunger and Environmental Nutrition 2012;7:271-292. [http://dx.doi.org/10.1080/19320248.2012.702448]

29. Bohle HG, Downing TE, Watts MJ. Climate change and social vulnerability: Towards a sociology and geography of food insecurity. Global Evironmental Change 1994:4:37-48. [http://dx.doi.org/10.1016/09593780(94)90020-5]

30. Desada H, Sewankambo N, eds. CIGI (The Centre for International Government Innovation) Specia Report: Climate Change in Africa: Adaptation, Mitigation and Governance Challenges. Waterloo, Canad CIGI, 2009

31. Thomas DSG, Tywman C. Equity and justice in climate change adaptation amongst natural resourcedependent societies. Global Environmental Change 2005;5:115-124. [http://dx.doi.org/10.1016/j. gloenvcha.2004.10.001]

32. Consultative Group on International Agricultural Research (CGIAR). http://www.cgiar.org (accessed 25 June 2014).

33. Marcus TS. Community Orientated Primary Care: Origins and History. Pretoria: Minuteman Press 2014.

.

35. The Times (UK). Global warming threat to health. 29 March 2014;12:01. http://www.thetimes.co.uk/tto/ opinion/letters/article4048102.ece (accessed 9 July 2014).

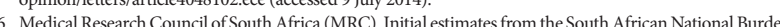

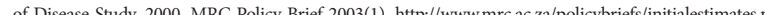

